\title{
Fecundity and offspring ploidy in matings among diploid, triploid and tetraploid Chamerion angustifolium (Onagraceae): consequences for tetraploid establishment
}

\author{
TRACY L. BURTON \& BRIAN C. HUSBAND \\ Department of Botany, University of Guelph, Guelph, Ontario, Canada N1G 2W1
}

\begin{abstract}
Models of polyploid evolution indicate that tetraploids are more likely to establish within diploid populations when they are formed recurrently through the union of unreduced $(n=2 n)$ gametes. To account for the coexistence of diploids and tetraploids in populations of Chamerion angustifolium, diploid, triploid and tetraploid plants were crossed in all possible combinations and fecundity and ploidy using flow cytometry of the resulting progeny were measured. Combined with previous data on cytotype fitness, these data were used in a simulation to examine the impact of unreduced gametes on tetraploid evolution. Seed set per fruit was highest in $2 x \times 2 x$ crosses $(69 \%)$, intermediate in $4 x \times 4 x$, $2 \mathrm{x} \times 4 \mathrm{x}$ and $3 \mathrm{x} \times 4 \mathrm{x}$ crosses (range, 11-35\%) and lowest in $3 \mathrm{x} \times 2 \mathrm{x}$ and $3 \mathrm{x} \times 3 \mathrm{x}$ crosses (range, $1-10 \%)$. Offspring were diploid $(94 \%)$ or triploid $(6 \%)$ in $2 \mathrm{x} \times 2 \mathrm{x}$ crosses, diploid $(17.5 \%)$, triploid $(56 \%)$ or tetraploid $(26.5 \%)$ in $3 x \times 2 x$ crosses, and triploid $(53 \%)$ and tetraploid $(44 \%)$ in all others $(4 \mathrm{x} \times 4 \mathrm{x}, 3 \mathrm{x} \times 4 \mathrm{x}, 2 \mathrm{x} \times 4 \mathrm{x})$, indicating that some gametes are unreduced, particularly in triploids. Forty-two percent of offspring, from three different crosses, had DNA contents greater than tetraploids. Computer simulations based on these results showed that unreduced gamete formation via triploids in $C$. angustifolium can promote the coexistence of diploids and tetraploids, but, due to law triploid fitness, is insufficient to overcome tetraploid minority disadvantage.
\end{abstract}

Keywords: computer simulation, fitness, flow cytometry, mating relationships, polyloid evolution, triploids.

\section{Introduction}

Research on polyploid evolution has seen renewed interest in the last two decades owing in part to the development of theoretical models that examine the ecological and genetic factors regulating the spread of polyploids and coexistence with their diploid progenitors (Fowler \& Levin, 1984; Felber, 1991; Rodriguez, 1996). In general, they indicate that, assuming random mating, coexistence is inhibited by a frequency-dependent mating disadvantage experienced by the rare cytotype (initially the tetraploid). This selective force arises because matings between diploids and tetraploids yield inviable triploid progeny ( $=$ triploid block) and the rare cytotype incurs a larger portion of hybrid matings (Levin, 1975; Felber, 1991). Three factors that could potentially overcome this barrier and enhance the likelihood that tetraploids will become established or

*Correspondence. E-mail: bhusband@uoguelph.ca coexist with diploids in sympatry are: (i) prezygotic mating barriers (Fowler \& Levin, 1984); (ii) increased relative fitness of the rare cytotype (Felber, 1991); and (iii) recurrent production of polyploids via unreduced gametes (Felber, 1991; Soltis \& Soltis, 1999), which is the focus of this study.

The most common mechanism of polyploid formation is believed to be through fertilizations that involve unreduced gametes (Harlan \& de Wet, 1975; Bretagnolle \& Thompson, 1995; Ramsey \& Schemske, 1998). Unreduced gametes possess the somatic chromosome number $(n=2 n)$ and are formed as a result of meiotic dysfunction, induced by genetic or environmental factors (Bretagnolle \& Thompson, 1995). Autotetraploids, specifically, may be produced through two recognized pathways, distinguished by the number of steps required (Ramsey \& Schemske, 1998). The first pathway involves the union of two unreduced gametes produced by diploids. This process results in the production of tetraploids within a single step. Alternatively, tetraploids 
may arise within two steps, from matings involving triploids, themselves the result of a union between a reduced and an unreduced gamete. Most gametes produced by triploids are nonfunctional, owing to unbalanced chromosome numbers; however, triploids may also produce gametes with either one $(n=\mathrm{x})$ or two $(n=2 \mathrm{x})$ chromosome sets as well as unreduced $(n=3 \mathrm{x})$ gametes. Therefore, triploids may produce tetraploid offspring when selfed or crossed to diploids or tetraploids. Because the probability of two $2 n$ gametes uniting is expected to be low, researchers have hypothesized that triploids will play an important role in tetraploid formation and evolution (Harlan \& de Wet, 1975). However, the significance of these mechanisms has been studied in a few wild species.

The perennial, self-compatible, herbaceous plant Chamerion angustifolium (Onagraceae) consists primarily of diploid $(2 n=2 \mathrm{x}=36)$ and tetraploid $(2 n=4 \mathrm{x}=72)$ cytotypes (Flint, 1980; Husband \& Schemske, 1998). In North America, these cytotypes are usually geographically separated, with diploids occurring at higher latitudes and altitudes (Mosquin, 1966; Mosquin \& Small, 1971). However, a zone of contact exists between the two cytotypes, which extends across North America near the southern limit of the boreal forest and south along the Rocky Mountains. In this zone, diploids, triploids and tetraploids are found in close proximity and frequently co-occur within the same populations (Husband \& Schemske, 1998).

Experimental studies have shown that in mixed populations rare cytotypes experience a strong mating disadvantage (Husband, 2000) as a consequence of the low viability of diploid $\times$ tetraploid matings. In light of this, a series of studies was undertaken to determine which factors promote the maintenance of tetraploids and diploids in mixed populations. A field study revealed strong prezygotic barriers such as divergence in flowering time and pollinator foraging behaviour, which likely diminish the frequency of diploid $\times$ tetraploid matings (Husband \& Schemske, 2000). In addition, a greenhouse study indicated that tetraploids were only two-thirds as fit as diploids (Burton \& Husband, 2000). However, no data are available on the rate of tetraploid formation via unreduced gametes. The importance of this process is heightened by the observation that triploids are often detected in mixed populations and may provide an added pathway through which tetraploids are produced.

The objective of this study was to examine the outcome of matings between experimentally generated diploid, triploid and tetraploid C. angustifolium and consider the implications for the formation of tetraploids in this species. Specifically, four questions were posed: (i) what are the fecundities of matings between diploid, triploid and tetraploid individuals? and (ii) what are the offspring ploidies generated from matings between diploid, triploid and tetraploid individuals? Then, using computer simulations, we asked: (iii) what effect does including fertile triploids have on the establishment of tetraploids in diploid populations? and (iv) what are the combined effects of the above mating outcomes and fitness differences, estimated from a previous study, on the establishment of tetraploids in diploid populations of $C$. angustifolium?

\section{Materials and methods}

\section{Source of diploid and polyploid parents}

In order to create the diploid, triploid and tetraploid parents used in this study, 30 seed families of C. angustifolium were collected from two populations, one diploid (D2) and one tetraploid (T26), growing in close proximity on the Beartooth Pass, Wyoming (Husband \& Schemske, 1997). Several seeds from each family were germinated and grown to flowering in the University of Guelph greenhouses. A number of maternal families had seeds that did not germinate. A total of 21 diploid and 21 tetraploid plants, each from a different seed family, were used in the experiment. Each diploid was paired with a randomly chosen tetraploid, and the two plants were crossed reciprocally as well as with a randomly selected plant of the same ploidy. Diploid, triploid and tetraploid plants were generated from the $2 \mathrm{x} \times 2 \mathrm{x}, 2 \mathrm{x} \times 4 \mathrm{x}, 4 \mathrm{x} \times 2 \mathrm{x}$ and $4 \mathrm{x} \times 4 \mathrm{x}$ crosses, respectively. The ploidy of each plant used in the study was confirmed by estimating its relative DNA content as fluorescence, using a DNA-specific fluorochrome (propidium iodide) and flow cytometry (Burton \& Husband, 1999, 2000). Mean (SE) fluorescence, relative to a chicken red blood cell standard, for plants used in this study was $1.23 \pm 0.04$ for diploids, $1.61 \pm 0.07$ for triploids with a diploid maternal parent (hereafter $3 x[2 x]), 1.71 \pm 0.05$ for triploids with a tetraploid maternal parent (hereafter $3 x[4 x]$ ) and $2.60 \pm 0.09$ for tetraploids. The mean fluorescence values fell within the expected range of values for diploids, triploids and tetraploids based on a previous survey of plants of known ploidy (Husband \& Schemske, 2000).

\section{Crossing design}

Twenty-five plants of each ploidy (2x, 3x[2x], 3x[4x] and $4 \mathrm{x}$ ) were randomly chosen, transplanted into $1-\mathrm{L}$ pots and grown to flowering (approximately nine weeks). After losses resulting from transplanting, there were 141 plants used in the experiment, including 15 triploids $(3 \mathrm{x}[2 \mathrm{x}]), 12$ triploids $(3 \mathrm{x}[4 \mathrm{x}]), 17$ diploids and 
14 tetraploids. Plants were crossed in all possible ploidy combinations, including reciprocal crosses where appropriate. Each plant served as a maternal and a paternal parent. A maximum of three different treatments was applied per maternal plant and each was replicated on two flowers. Pollen from two recently dehisced anthers was used to cross-pollinate each stigma. For each maternal parent, the paternal parent of the specified ploidy was chosen at random. Flowers used in all pollination treatments were also chosen randomly. In total, 546 replicated pollinations were completed, which included $262 \mathrm{x} \times 2 \mathrm{x}$ crosses, $164 \mathrm{x} \times 4 \mathrm{x}$ crosses, 31 $2 \mathrm{x} \times 4 \mathrm{x}$ crosses, $422 \mathrm{x} \times 3 \mathrm{x}[2 \mathrm{x}]$ crosses, $302 \mathrm{x} \times 3 \mathrm{x}[4 \mathrm{x}]$ crosses, $314 \mathrm{x} \times 3 \mathrm{x}[2 \mathrm{x}]$ crosses, $224 \mathrm{x} \times 3 \mathrm{x}[4 \mathrm{x}]$ crosses, 22 $3 x[2 x] \times 3 x[2 x]$ crosses, $193 x[4 x] \times 3 x[4 x]$ crosses and 34 $3 \mathrm{x}[2 \mathrm{x}] \times 3 \mathrm{x}[4 \mathrm{x}]$ crosses.

\section{Seed set and germination}

For all fruits, seeds were cleaned of hairs and counted. Seeds were designated as either filled or unfilled based on a visual assessment, using criteria used by Burton \& Husband (2000). Fruit set was estimated as the proportion of flowers pollinated that resulted in fruit with at least one seed. Seed set was estimated as the proportion of ovules per fruit forming full seeds.

Germination frequency was estimated by sowing 25 full seeds for each maternal parent $\times$ cross combination onto moist filter paper in each of three Petri dishes and incubating them in a growth chamber ( $16 \mathrm{~h}$ daylight at $25^{\circ} \mathrm{C}$ and $8 \mathrm{~h}$ dark at $20^{\circ} \mathrm{C}$ ). For crosses that yielded less than 75 seeds, all full seeds were sown. After one week and again at two weeks, germination was assessed. Seeds were classified as having successfully germinated once the radicle had emerged (Husband \& Schemske, 1997). Variation in fruit set among cross types was evaluated using a chi-squared test. Variation among cross types in mean seed set per fruit was examined using an analysis of variance (ANOVA) and Scheffés means comparison. Mean germination was compared using a nonparametric Kruskal-Wallis test, as residuals were not normally distributed. All viable seedlings were potted and grown for DNA content measurements.

\section{Flow cytometry}

One full-sized leaf from each plant was used to estimate DNA content (measured as fluorescence) using flow cytometry (Keeler et al., 1987; Arumuganathan \& Earl, 1991; Burton \& Husband, 1999). Nuclei were isolated, stained with propidium iodide and fluorescence measured for each sample (Burton \& Husband, 1999). Chicken red blood cells (CRBC), prepared in a similar way, were run as an external standard after every 5-10 leaf samples. Fluorescence values per sample were converted to relative fluorescence values by expressing the mean as a proportion of the CRBC standard analysed during the same run (hereafter referred to as relative fluorescence). Each offspring was classified by ploidy based on DNA content. While some aneuploid offspring will undoubtedly arise from crosses involving triploids, four ploidy classes (diploid, triploid, tetraploid, > tetraploid) were used herein to ensure adequate sample sizes and to minimize errors from assigning ploidy based on DNA content. The expected ranges of relative fluorescence (DNA content) for diploids, triploids and tetraploids was previously determined from the parents of the plants used in this study by Burton \& Husband (2000; relative fluorescence of diploids, 0.85-1.19, triploids, 1.20-2.06; tetraploids, 2.07-3.32).

\section{Computer simulations}

The effect of variation in fecundity and offspring ploidy among cytotype crosses on tetraploid evolution in $C$. angustifolium was examined using computer simulations. Each simulation involved initiating a population of $n=100$ individuals with nonoverlapping generations, and randomly assigning each individual a ploidy (diploid, triploid or tetraploid) according to a prescribed initial frequency. In each generation, the population was subject to ploidy-specific viability and fertility selection and the fate of each individual was monitored throughout. Viability was defined as the likelihood that an embryo survives to reproductive maturity and ranged from zero to one. Fertility was defined as the frequency of viable gametes produced relative to diploids and ranged from zero to one. Finally, plants surviving fertility and viability selection were mated and progeny generated to form the next generation. During reproduction, $n$ mating pairs were selected randomly from within the population and a single progeny was chosen to replace them in the next generation. Progeny ploidy was determined by sampling randomly from the ploidy distributions derived from the crossing experiment (see results). Possible progeny ploidies were restricted to being diploid, triploid or tetraploid as the frequency of aneuploidy was not measured and individuals whose ploidy exceeds $4 \mathrm{x}$ are assumed to be inviable based on the fact that they have not been found in natural populations of $C$. angustifolium in North America (Husband \& Schemske, 1998).

The frequencies of cytotypes in the simulated population were recalculated after viability selection but before fertility selection each generation, because this would be comparable to the time when most field surveys are conducted. The equilibrium frequency of tetraploids was determined after 100 generations, as this 
duration exceeded the number of generations required to observe a change in cytotype frequencies $<0.001$. While the structure of the simulated population may not reflect the current population cytotype structure in natural populations of $C$. angustifolium, it is consistent in structure with previous models (Felber, 1991; Felber \& Bever, 1997) and thus allowed the likelihood of tetraploid establishment to be compared with earlier theoretical studies.

Two sets of simulations were conducted. In the first set, the effect of the observed ploidy distributions of progeny from $2 \mathrm{x}, 3 \mathrm{x}$ and $4 \mathrm{x}$ matings on tetraploid evolution were examined by quantifying the equilibrium tetraploid frequencies under four extreme fertility and viability conditions:

I diploid fertility $=1$, tetraploid fertility $=0$, all viabilities $=1$;

II diploid fertility $=1$, tetraploid fertility $=1$, all viabilities $=1$;

III diploid viability $=1$, tetraploid viability $=0$, all fertility $=1$;

IV diploid viability $=1$, tetraploid viability $=1$, all fertility $=1$;

Initially, triploid fertility (in cases I \& II) and triploid viability (in cases III \& IV) were set to zero to duplicate earlier models (Felber, 1991). Equilibrium frequencies were then examined with successive increments $(0.2)$ of triploid fertility or viability. Simulations began with a completely diploid population, and all parameter combinations were replicated with 100 simulations.

In the second set of simulations, tetraploid establishment in C. angustifolium, specifically, was modelled. For this simulation, the progeny ploidy distributions observed in this study were again used. However, the viability and fertility fitnesses used were taken from a previous study (Burton \& Husband, 2000). Viability measures were the product of seed maturation, germination and plant survival, while fertility included measures of pollen number, pollen stainability and biomass (which was correlated with flower number) (Burton \& Husband, 2000). In this simulation run, all viabilities were expressed relative to diploids such that diploid viability $=1$, triploid viability $=0.31$ and tetraploid viability $=0.61$. Fertilities were 1 for diploids, 0.20 for triploids and 0.97 for tetraploids. The only parameter varied in the simulation was the initial frequency of diploids $(0,0,2,0.4,0.6,0.8$, and 1$)$. In simulations in which the initial diploid frequency was less than one, all remaining individuals were designated as tetraploid. The equilibrium frequencies of diploids, triploids and tetraploids were determined for each simulation at generation 100. Each of the five initial diploid frequencies was replicated with 100 simulations.

\section{Results}

\section{Seed set and germination}

Virtually all flowers $(94 \% \pm 4 \%)$ that were pollinated yielded fruit. However, there was a significant difference among crosses in the proportion of pollinated flowers that set fruit $\left(\chi^{2}=65.1\right.$, d.f. $\left.=9, P<0.0001\right)$, ranging from $74 \%$ in $4 x \times 4 x$ crosses to $100 \%$ in $2 x \times 2 x$, $2 \mathrm{x} \times 4 \mathrm{x}, \quad 3 \mathrm{x}[2 \mathrm{x}] \times 2 \mathrm{x}, \quad 3 \mathrm{x}[2 \mathrm{x}] \times 3 \mathrm{x}[2 \mathrm{x}], \quad 3 \mathrm{x}[4 \mathrm{x}] \times 2 \mathrm{x}$ crosses.

Seed set differed significantly among the cross treatments (Table 1). Mean seed set in $2 \mathrm{x} \times 2 \mathrm{x}$ crosses $(0.69 \pm 0.04)$ was significantly higher than all other crosses. Seed set in $4 x \times 4 x(0.35 \pm 0.07)$ crosses was next highest and was statistically homogenous with other cross types that had intermediate seed set including both hybrid crosses $(2 \mathrm{x} \times 4 \mathrm{x}$, mean $=0.32 \pm 0.05$; $4 \mathrm{x} \times 2 \mathrm{x}$, mean $=0.25 \pm 0.05$ ), and three of the four reciprocal cross types between triploids and tetraploids $(3 \mathrm{x}[2 \mathrm{x}] \times 4 \mathrm{x}$, mean $=0.11 \pm 0.02 ; 4 \mathrm{x} \times 3 \mathrm{x}[4 \mathrm{x}]$, mean $=$ $0.12 \pm 0.05 ; \quad 3 x[4 x] \times 4 x, \quad$ mean $=0.17 \pm 0.03)$. The remaining cross types had seed set values ranging from $0.01(\mathrm{SE} \pm 0.01)$ to $0.10(\mathrm{SE} \pm 0.01)$ and all were statistically different from the $4 \mathrm{x} \times 4 \mathrm{x}$ crosses. This group included all crosses between triploids and diploids $(3 \mathrm{x}[4 \mathrm{x}] \times 2 \mathrm{x}, \quad 2 \mathrm{x} \times 3 \mathrm{x}[4 \mathrm{x}], \quad 2 \mathrm{x} \times 3 \mathrm{x}[2 \mathrm{x}], \quad 3 \mathrm{x}[2 \mathrm{x}] \times 2 \mathrm{x})$, those among triploids $(3 \mathrm{x}[4 \mathrm{x}] \times 3 \mathrm{x}[4 \mathrm{x}], 3 \mathrm{x}[2 \mathrm{x}] \times 3 \mathrm{x}[2 \mathrm{x}]$,

Table 1 Mean (SE) seed set per fruit for crosses among diploid, triploid and tetraploid cytotypes of Chamerion angustifolium. The cytotypes in parentheses indicate the ploidy of the maternal parent used to generate the triploid. Means not sharing the same superscript were significantly different as determined by an ANOVA and Sheffe's post hoc test

\begin{tabular}{lcrrr}
\hline & \multicolumn{4}{c}{ Paternal parent } \\
\cline { 2 - 5 } Maternal parent & \multicolumn{1}{c}{$2 \mathrm{x}$} & \multicolumn{4}{c}{$3 \mathrm{x}[2 \mathrm{x}]$} & \multicolumn{1}{c}{$3 \mathrm{x}[4 \mathrm{x}]$} & $\mathrm{x}$ \\
\hline $2 \mathrm{x}$ & $0.69^{\mathrm{a}} \pm 0.04$ & $0.10^{\mathrm{bf}} \pm 0.03$ & $0.02^{\text {bgik }} \pm 0.01$ & $0.32^{\text {eh }} \pm 0.05$ \\
$3 \mathrm{x}[2 \mathrm{x}]$ & $0.09^{\mathrm{bd}} \pm 0.01$ & $0.04^{\mathrm{dfg}} \pm 0.02$ & $0.01^{\text {bgik }} \pm 0.01$ & $0.11^{\text {efgikh }} \pm 0.02$ \\
$3 \mathrm{x}[4 \mathrm{x}]$ & $0.10^{\mathrm{bd}} \pm 0.01$ & $0.02^{\mathrm{dfi}} \pm 0.01$ & $0.01^{\mathrm{dfgik}} \pm 0.01$ & $0.17^{\text {efgikh }} \pm 0.03$ \\
$4 \mathrm{x}$ & $0.25^{\text {beh }} \pm 0.05$ & $0.01^{\mathrm{dfk}} \pm 0.01$ & $0.12^{\text {bgikh }} \pm 0.05$ & $0.35^{\mathrm{h}} \pm 0.07$ \\
\hline
\end{tabular}


$3 x[2 x] \times 3 x[4 x], \quad 3 x[4 x] \times 3 x[2 x])$ and one of the four crosses between triploids and tetraploids $(3 \mathrm{x}[2 \mathrm{x}] \times 4 \mathrm{x})$. There were no significant differences in seed set between reciprocal crosses for any cross type (Table 1). In addition, there were no significant differences in mean germination frequency among cross types based on a nonparametric Kruskal-Wallis test $(H=11.84$, $P>0.05$ ) (Table 2).

Fluorescence values did not differ between progeny of reciprocal crosses (Mann-Whitney $U$-tests, $P>0.05$ ) and therefore the reciprocals were pooled and mean fluorescence reported for only 10 cross types (Table 3 ). Of these 10 cross types, no data were obtained for one cross $(3 x[2 x] \times 3 x[2 x])$ and only one value was obtained for two others $(3 x[2 x] \times 3 x[4 x]$ and $3 x[2 x] \times 4 x)$, as a result of low germination and high mortality during transplanting. Mean relative fluorescence differed significantly among the remaining cross types based on a Kruskal-Wallis test $(H=120.52, P<0.0001)$ (Table 3$)$. The $2 \mathrm{x} \times 2 \mathrm{x}$ cross had the lowest mean relative fluorescence $(1.28 \pm 0.05)$, different from all other crosses, while $3 \mathrm{x}[2 \mathrm{x}] \times 4 \mathrm{x}$ crosses had the highest $(3.68$, but $n=1)$. There were no significant differences in mean fluorescence among $2 \mathrm{x} \times 4 \mathrm{x}(2.06 \pm 0.16), 3 \mathrm{x}[4 \mathrm{x}] \times 2 \mathrm{x}$ $(2.10 \pm 0.16)$ and $3 x[4 x] \times 3 x[4 x](1.82 \pm 0.10)$ crosses. Also, no significant differences in fluorescence were observed among $4 \mathrm{x} \times 4 \mathrm{x} \quad(3.25 \pm 0.13), \quad 3 \mathrm{x}[2 \mathrm{x}] \times 2 \mathrm{x}$ $(3.30 \pm 0.18)$ and $3 x[4 x] \times 4 x(3.36 \pm 0.13)$ crosses.

Forty-two percent of all progeny had fluorescence values above the expected range for tetraploids (2.073.32 ), and these occurred primarily in $4 x \times 4 x$, $3 x[2 x] \times 4 x$ and $3 x[4 x] \times 4 x$ crosses (Table 4). Of the remaining progeny, $25 \%$ were classified as triploid, $22 \%$ as tetraploid and $12 \%$ as diploid. There were significant differences among cross types in the proportion of diploids, triploids and tetraploids produced (reciprocal crossed pooled, $\chi^{2}=206.12$, d.f. $=24, P<0.0001$ ). Moreover, all crosses comprised more than one cytotype in their offspring. Progeny from $2 \mathrm{x} \times 2 \mathrm{x}$ crosses were diploid and triploid; $2 \mathrm{x} \times 3 \mathrm{x}[2 \mathrm{x}]$ and $2 \mathrm{x} \times 3 \mathrm{x}[4 \mathrm{x}]$ crosses resulted in diploid, triploid and tetraploid progeny, and all other crosses $(2 \mathrm{x} \times 4 \mathrm{x}, \quad 4 \mathrm{x} \times 4 \mathrm{x}, \quad 4 \mathrm{x} \times 3 \mathrm{x}[2 \mathrm{x}]$, $4 \mathrm{x} \times 3 \mathrm{x}[4 \mathrm{x}])$ produced triploid and tetraploid progeny (Table 4). Of the crosses resulting in triploid and tetraploid offspring, $4 \mathrm{x} \times 4 \mathrm{x}, 2 \mathrm{x} \times 4 \mathrm{x}$ and $2 \mathrm{x} \times 3 \mathrm{x}$ were mostly triploid, while progeny from both $3 \mathrm{x} \times 4 \mathrm{x}$ crosses were evenly distributed or predominantly tetraploid.

\section{Simulations}

Effect of increasing triploid fertility. Regardless of the fertility of tetraploids, relative to diploids $(2 \mathrm{x}=1,4 \mathrm{x}=0$ and $2 \mathrm{x}=1,4 \mathrm{x}=1$ ), tetraploids never became established in a diploid population when triploid fertility was 0 (Fig. 1a,b). The effect of triploid fertility on the equilibrium tetraploid frequency depended on the relative fitnesses of diploids and tetraploids. When

Table 3 Mean relative fluorescence values for cross types in Chamerion angustifolium. Fluorescence values are expressed relative to a chicken red blood cell standard. Fluorescence values in reciprocal crosses are pooled. The cytotypes in parentheses indicate the ploidy of the maternal parent used to generate the triploid. The Kruskal-Wallis test was used to compare means, $H=120.52, P<0.0001$. Means not sharing superscripted letters were significantly different as determined by a Mann-Whitney $U$-test $(P<0.01)$

\begin{tabular}{lc}
\hline Cross type & Fluorescence value $( \pm$ SE $)$ \\
\hline $2 \mathrm{x} \times 2 \mathrm{x}$ & $1.28 \pm 0.05^{\mathrm{a}}$ \\
$2 \mathrm{x} \times 4 \mathrm{x}$ & $2.06 \pm 0.16^{\mathrm{b}}$ \\
$4 \mathrm{x} \times 4 \mathrm{x}$ & $3.25 \pm 0.13^{\mathrm{c}}$ \\
$3 \mathrm{x}[2 \mathrm{x}] \times 2 \mathrm{x}$ & $3.30 \pm 0.18^{\mathrm{c}}$ \\
$3 \mathrm{x}[2 \mathrm{x}] \times 4 \mathrm{x}$ & 3.68 \\
$3 \mathrm{x}[4 \mathrm{x}] \times 2 \mathrm{x}$ & $2.10 \pm 0.16^{\mathrm{b}}$ \\
$3 \mathrm{x}[4 \mathrm{x}] \times 4 \mathrm{x}$ & $3.36 \pm 0.13^{\mathrm{c}}$ \\
$3 \mathrm{x}[2 \mathrm{x}] \times 3 \mathrm{x}[2 \mathrm{x}]$ & - \\
$3 \mathrm{x}[2 \mathrm{x}] \times 3 \mathrm{x}[4 \mathrm{x}]$ & 3.26 \\
$3 \mathrm{x}[4 \mathrm{x}] \times 3 \mathrm{x}[4 \mathrm{x}]$ & $1.82 \pm 0.10^{\mathrm{b}}$ \\
\hline
\end{tabular}

Table 2 Mean $( \pm \mathrm{SE}$ ) seed germination for crosses among diploid, triploid and tetraploid cytotypes of Chamerion angustifolium. Column headings are paternal parents, row headings are maternal parents. The cytotypes in parentheses indicate the ploidy of the maternal parent used to generate the triploid. The Kruskal-Wallis test was used to compare means, $H=11.84, P>0.05$

\begin{tabular}{lcccc}
\hline & \multicolumn{4}{c}{ Paternal parent } \\
\cline { 2 - 5 } Maternal parent & $2 \mathrm{x}$ & $3 \mathrm{x}[2 \mathrm{x}]$ & $3 \mathrm{x}[4 \mathrm{x}]$ & $4 \mathrm{x}$ \\
\hline $2 \mathrm{x}$ & $0.52 \pm 0.09$ & $0.40 \pm 0.06$ & $0.38 \pm 0.09$ & $0.60 \pm 0.15$ \\
$3 \mathrm{x}[2 \mathrm{x}]$ & $0.36 \pm 0.05$ & $0.19 \pm 0.07$ & $0.50 \pm 0.50$ & $0.50 \pm 0.09$ \\
$3 \mathrm{x}[4 \mathrm{x}]$ & $0.41 \pm 0.06$ & $0.34 \pm 0.17$ & $0.27 \pm 0.16$ & $0.36 \pm 0.07$ \\
$4 \mathrm{x}$ & $0.35 \pm 0.09$ & $0.41 \pm 0.08$ & $0.50 \pm 0.07$ & $0.49 \pm 0.10$ \\
\hline
\end{tabular}

(C) The Genetics Society of Great Britain, Heredity, 87, 573-582. 
Table 4 Distribution of offspring ploidies in crosses between different Chamerion angustifolium cytotypes. For triploid parents, the cytotype of the maternal parent is indicated in square parentheses. Frequencies of offspring ploidies were calculated with and without (round parentheses) the $>4 \mathrm{x}$ cateogory included. Ploidy frequencies with the $>4 \mathrm{x}$ category excluded were used to represent offspring production in the computer simulations

\begin{tabular}{lccccccc}
\hline \multirow{2}{*}{$\begin{array}{l}\text { Offspring } \\
\text { ploidy }\end{array}$} & $2 \mathrm{x} \times 2 \mathrm{x}$ & $2 \mathrm{x} \times 4 \mathrm{x}$ & $4 \mathrm{x} \times 4 \mathrm{x}$ & $2 \mathrm{x} \times 3 \mathrm{x}[2 \mathrm{x}]$ & $2 \mathrm{x} \times 3 \mathrm{x}[4 \mathrm{x}]$ & $4 \mathrm{x} \times 3 \mathrm{x}[2 \mathrm{x}]$ & $4 \mathrm{x} \times 3 \mathrm{x}[4 \mathrm{x}]$ \\
\cline { 2 - 7 } & 34 & 36 & 44 & 41 & 20 & 25 & 70 \\
$n$ & $0.94(0.94)$ & $0.00(0.00)$ & $0.00(0.00)$ & $0.19(0.19)$ & $0.15(0.16)$ & $0.00(0.00)$ & $0.06(0.14)$ \\
$2 \mathrm{x}$ & $0.06(0.06)$ & $0.83(0.83)$ & $0.23(0.63)$ & $0.65(0.65)$ & $0.45(0.47)$ & $0.16(0.50)$ & $0.34(0.86)$ \\
$3 \mathrm{x}$ & $0.00(0.00)$ & $0.17(0.17)$ & $0.14(0.38)$ & $0.16(0.16)$ & $0.35(0.37)$ & $0.16(0.50)$ & $0.00(0.00)$ \\
$4 \mathrm{x}$ & $0.00-$ & $0.00-$ & $0.64-$ & $0.00-$ & $0.05-$ & $0.68-$ & $0.60-$ \\
$>4 \mathrm{x}$ & & & &
\end{tabular}
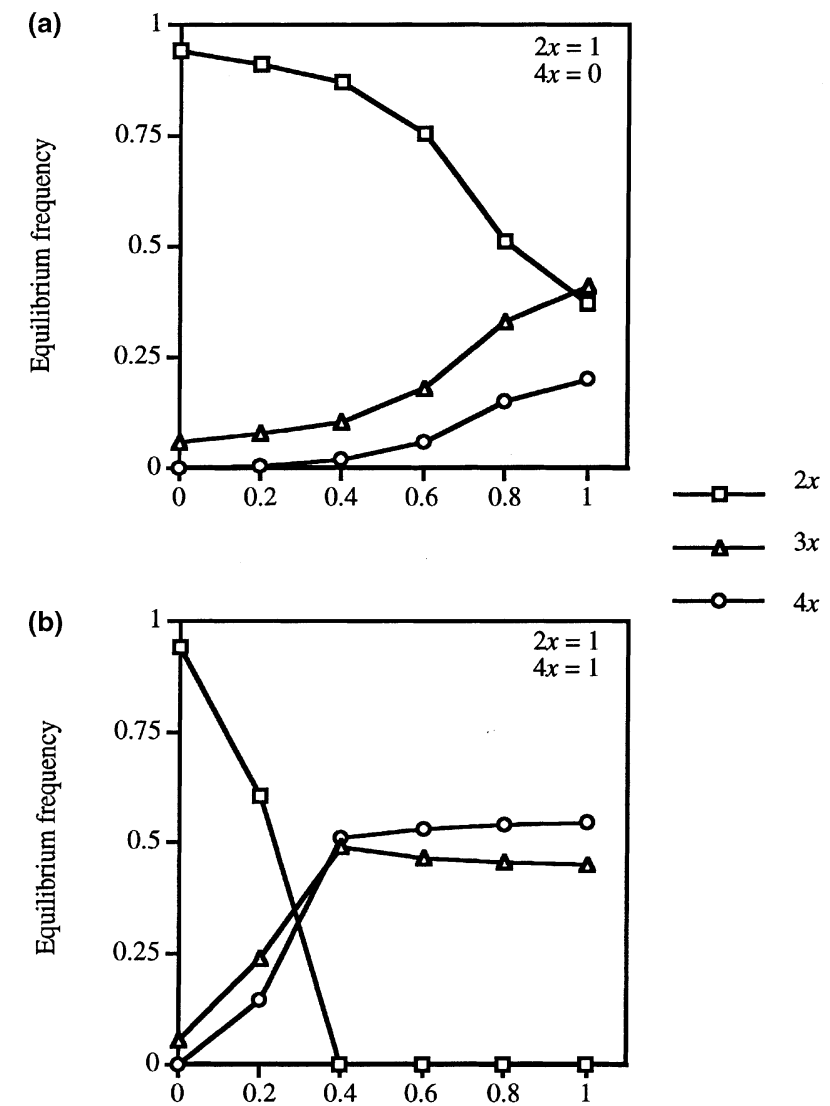

Triploid fertility

Fig. 1 Equilibrium frequencies of diploids, triploids and tetraploids after 100 generations of a computer simulation.

(a) Diploid fertility was one, tetraploid fertility was zero and triploid fertility ranged from zero to one. (b) Diploid fertility was one, tetraploid fertility was one and triploid fertility ranged from zero to one. Viability for diploids, triploids and tetraploids was held constant at one. Each simulation was replicated 100 times. Standard errors are not visible at this scale and therefore were excluded. tetraploid relative fertility $=0$ and triploid fertility $>0$ $(2 \mathrm{x}=1,4 \mathrm{x}=0)$, all three cytotypes coexisted at equilibrium (Fig. 1a). Increasing triploid fertility towards one reduced the equilibrium frequency of diploids and increased the equilibrium frequency of triploids and tetraploids. At a triploid fertility of one, $20 \%$ of the individuals were tetraploid.

When the relative fertility of tetraploids $=1(2 \mathrm{x}=1$, $4 \mathrm{x}=1$ ), and triploid fertility $>0$, equilibrium populations contained $2 \mathrm{x}, 3 \mathrm{x}$ and $4 \mathrm{x}$ individuals (Fig. 1b). When triploid fertility exceeded 0.4 , diploids were excluded, and triploids and tetraploids were represented at almost equal frequencies $(45 \%$ and $55 \%$, respectively). However, there was no value of triploid fertility that resulted in tetraploid fixation.

Effect of increasing triploid viability. The effect of triploid viability on equilibrium frequencies of tetraploids depended on the viability of tetraploids, relative to diploids. When the relative viability of tetraploids $=0$, and triploid viability $=0$, the equilibrium frequency of tetraploids was zero (Fig. 2a). However, all three cytotypes coexisted at equilibrium when the viability of triploids $>0.2$. Furthermore, when triploid viability was increased towards one, the equilibrium frequency of tetraploids increased to $\sim 10 \%$, whereas diploids and triploids had nearly equal and higher frequencies (c. $45 \%)$.

When the relative viability of tetraploids was one, tetraploids comprised approximately $20 \%$ of the population, even when triploid viability $=0$ (Fig. 2b). When triploid viability was increased to 0.2 , tetraploid equilibrium frequency increased to approximately $75 \%$. Above a triploid viability of 0.2 , the tetraploid equilibrium frequency declined slightly, while still remaining the predominant cytotype $(55 \%)$. In addition, the frequency of diploids fell to zero at a triploid viability of 0.4 , leaving only $3 \mathrm{x}$ and $4 \mathrm{x}$ individuals in almost equal frequencies ( $45 \%$ and $55 \%$, respectively). 

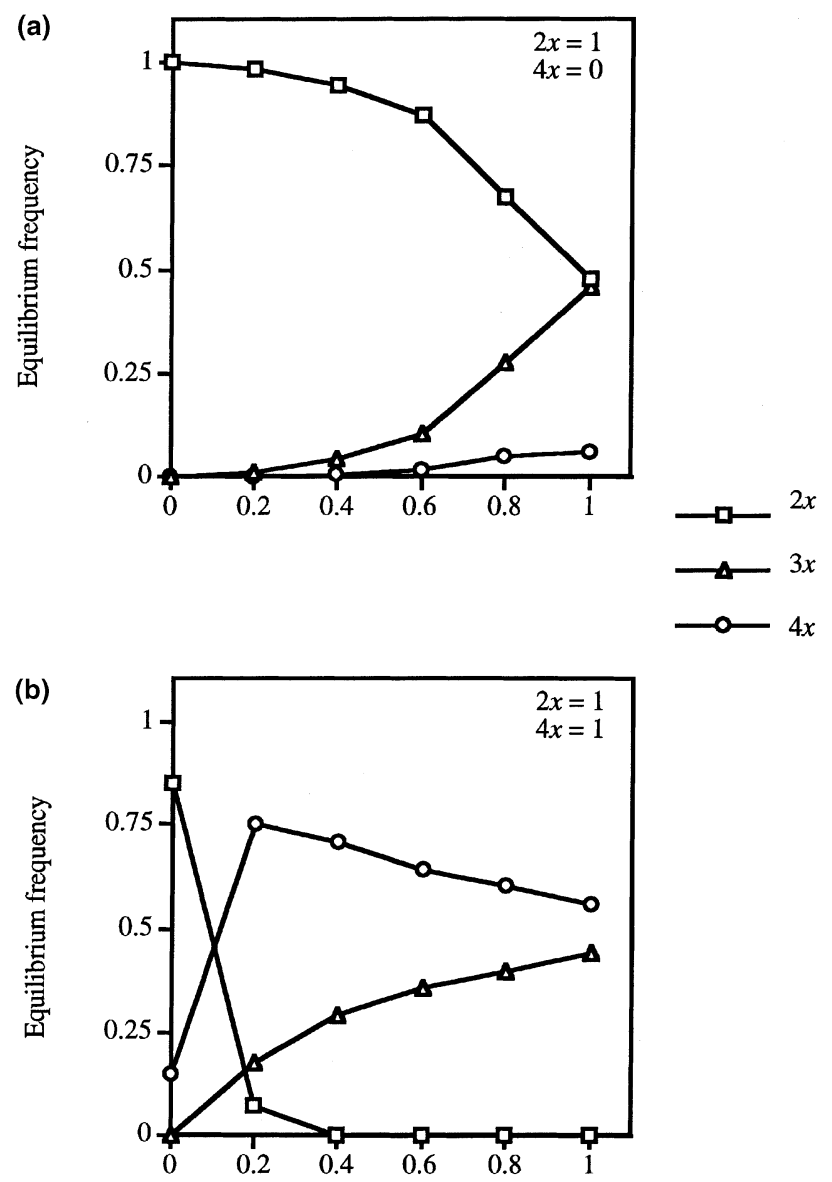

Triploid viability

Fig. 2 Equilibrium frequencies of diploids, triploids and tetraploids after 100 generations of a computer simulation. (a) Diploid viability was one, tetraploid viability was zero and triploid viability ranged from zero to one. (b) Diploid viability was one, tetraploid viability was one and triploid viability ranged from zero to one. Fertility for diploids, triploids and tetraploids was held constant at one. Each simulation was replicated 100 times. Standard errors were not visible at this scale and therefore were excluded.

\section{Tetraploid establishment in C. angustifolium}

Using the viability, fertility and estimates for diploid, triploid and tetraploid $C$. angustifolium (Burton \& Husband, 2000), the likelihood of tetraploid establishment was examined by determining the initial frequency of tetraploids required to achieve tetraploid establishment and fixation (Fig. 3). When initial diploid frequencies were greater than 0.4 (tetraploid $<0.6$ ), populations went to near-diploid fixation ( $>95 \%)$; triploids were maintained at a low frequency $(<5 \%)$ and tetraploids were excluded or nearly so. When the initial diploid frequency was less than 0.4 (i.e. tetrap-

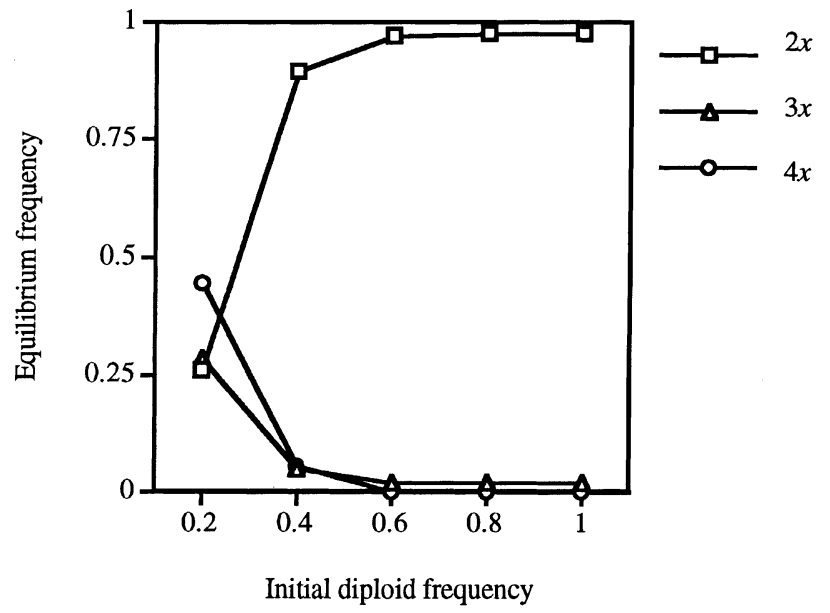

Fig. 3 Equilibrium frequency of diploids, triploids and tetraploids as a function of initial diploid frequencies when cytotype viabilities were $1.00,0.31$ and 0.67 and fertilities were $1.00,0.20$ and 0.97 for diploids, triploids and tetraploids, respectively.

loids > 0.6), diploids, triploids and tetraploids were present with tetraploids being the predominant cytotype (approximately 50\%).

\section{Discussion}

With respect to seed production, the 10 cross combinations in this study fell into one of three groups. In general, $2 \mathrm{x} \times 2 \mathrm{x}$ crosses yielded the highest seed set, $4 \mathrm{x} \times 4 \mathrm{x}, 2 \mathrm{x} \times 4 \mathrm{x}$ and $3 \mathrm{x} \times 4 \mathrm{x}$ crosses had intermediate values and crosses between $3 x$ plants or between $3 x$ and $2 x$ plants had very low seed set. Patterns of seed set for $2 \mathrm{x} \times 2 \mathrm{x}, 2 \mathrm{x} \times 4 \mathrm{x}$ and $4 \mathrm{x} \times 4 \mathrm{x}$ crosses and their statistical relations were comparable to those reported in Burton $\&$ Husband (2000). This reaffirms an earlier conclusion that intercytotype crosses are not infertile, and that while triploid fitness is lower in this species, most of its effects are exhibited at stages later than seed maturation (e.g. pollen production, pollen viability) (Burton \& Husband, 2000). Most crosses that involved at least one triploid parent exhibited low but nonzero fecundity overall, especially $3 \mathrm{x} \times 2 \mathrm{x}$ and $3 \mathrm{x} \times 3 \mathrm{x}$ crosses. This is consistent with studies reviewed by Ramsey \& Schemske (1998), that observe some viable seed in $3 \mathrm{x} \times 3 \mathrm{x}$ and $3 \mathrm{x} \times 2 \mathrm{x}$ crosses. Interestingly in the present study, crosses between triploid and tetraploid plants (reciprocals included) were surprisingly fecund, compared to crosses between triploids and diploids. This pattern is the reverse of Sato et al. (1993) who reported higher seed yield in $3 \mathrm{x} \times 2 \mathrm{x}$ than $3 \mathrm{x} \times 4 \mathrm{x}$ crosses. This may be expected if the gametes of triploids are largely diploid, and therefore capable of siring $3 \mathrm{x}$ or $4 \mathrm{x}$ offspring when 
crossed with a tetraploid, a result born out by our analysis of offspring ploidy (discussed below).

Germination rate ranged from 27 to $60 \%$ among cross types in Chamerion angustifolium; however, there were no significant differences among means. This result is in contrast to a previous finding (Burton \& Husband, 2000 ), in which there were significant differences between $2 \mathrm{x} \times 2 \mathrm{x}$ and $2 \mathrm{x} \times 4 \mathrm{x}$, and $4 \mathrm{x} \times 4 \mathrm{x}$ and $2 \mathrm{x} \times 4 \mathrm{x}$ crosses. The discrepancy is the result primarily of reduced germination in both of the intracytotype crosses of this study $(2 \mathrm{x} \times 2 \mathrm{x}: 52 \% ; 4 \mathrm{x} \times 4 \mathrm{x}: 49 \%)$, compared to the previous study $(2 \mathrm{x} \times 2 \mathrm{x}: 83 \% ; 4 \mathrm{x} \times 4 \mathrm{x}: 75 \%)$. It is difficult to account for the lack of a cross type effect; however, the seed was stored for different periods prior to these experiments and the germination trials themselves were conducted at different times. Although all seeds were stored similarly, variations in humidity and temperature during storage have affected germination rates differently in the past.

All cross types that yielded progeny for flow cytometric analysis had more than one ploidy in their offspring. This variation may arise either from methodological and interpretive difficulties associated with flow cytometry (i.e. apparent ploidy variation) or due to the biological features of this species under the environment in which it was investigated. Flow cytometry has been used frequently in studies of the population biology of polyploidy (Keeler et al., 1987; Maceira et al., 1992; Burton \& Husband, 1999). However, errors may occur in the estimate of DNA content that are associated with the source of material (age, location), running conditions (e.g. machine, staining procedure, density of nuclei, voltage, etc.) as well as through misclassifications into ploidy categories. In order to minimize such occurrences, recognized nuclei standards (chicken red blood cells) were used, and DNA content of each sample was expressed relative to those standards. To ensure the accuracy of ploidy assignments, (i) expected DNA content ranges for diploids, triploids and tetraploids were generated using a large number of individuals from the parental generation ( $>15 /$ ploidy), and (ii) because there was some overlap in expected DNA content of diploids and triploids (Burton \& Husband, 2000), plants in this region were classified as diploid, making present estimates of polyploidy conservative. Given these precautions and the fact that they were applied similarly across all cross types, the results observed are believed to be an accurate depiction of gamete quality in diploid, triploid and tetraploid $C$. angustifolium. However, it is recognized that while all offspring were assigned to one of four euploid classes, offspring may deviate from the euploid number to a limited extent.
Variation in offspring ploidy observed in all crosses suggests there is considerable variation in gamete quality and, specifically, the frequency of unreduced gametes. For example, six percent of progeny from $2 \mathrm{x} \times 2 \mathrm{x}$ crosses were identified as triploid ( $94 \%$ were diploid). These triploid offspring are likely the result of the union between reduced and unreduced $(n=2 n)$ gametes. Assuming that reduced and unreduced gametes associate randomly, it is estimated that the effective frequency of unreduced gametes in diploid $C$. angustifolium is approximately $3 \%$. The existence of unreduced gametes in diploid plants is further confirmed by the distribution of ploidies among offspring from $2 \mathrm{x} \times 4 \mathrm{x}$ crosses, which show a substantial number of tetraploids in addition to the expected triploid progeny. In a review by Ramsey \& Schemske (1998), the frequency of unreduced gametes in autopolyploid species was estimated to be 0.005 , nearly an order of magnitude smaller than the present estimate. This highlights the fact that estimates can vary widely depending on the species as well as the environment in which the crosses were conducted.

Although the fecundity of crosses involving triploids is generally low (especially $3 \mathrm{x} \times 3 \mathrm{x}$ and $3 \mathrm{x} \times 2 \mathrm{x}$ crosses), the present study indicates that their gametes can function in fertilization and can produce progeny of variable ploidy. Most notable is the fact that crosses with diploids yield offspring of all three cytotypes. A similar pattern has been observed in $3 \mathrm{x} \times 2 \mathrm{x}$ crosses in several other studies (Ramsey \& Schemske, 1998). This pattern suggests that triploids not only produce gametes that are $x, 2 x$ and $3 x$, but that they are produced in different proportions. Assuming that gametes from diploids are mostly reduced $(n=\mathrm{x})$, the frequency of $2 \mathrm{x}, 3 \mathrm{x}$ and $4 \mathrm{x}$ offspring (mean $=18 \%, 56 \%$ and $26 \%$ ) from the $2 \mathrm{x} \times 3 \mathrm{x}$ crosses should be a reasonable measure of the frequency of $x, 2 x$, and $3 x$ gametes produced by triploids. In $4 x \times 3 x$ crosses, diploid progeny were not detected, presumably because $n=x$ gametes in tetraploids are extremely rare (although the $4 \mathrm{x} \times 4 \mathrm{x}$ crosses are not clear on this), and therefore so are diploid offspring. In addition, the frequency of tetraploids was higher in $4 \mathrm{x} \times 3 \mathrm{x}$ than in $2 \mathrm{x} \times 3 \mathrm{x}$ crosses, as found in other studies (Ramsey \& Schemske, 1998), suggesting that they are produced by the union of $n=2 \mathrm{x}$ gametes, which are most common in triploids.

One of the surprising results of this study was the high frequency of offspring whose DNA content exceeded that expected for tetraploids. However, the result may not be completely unexpected, given that one-quarter of the gametes produced by triploids appear to be diploid $(2 \mathrm{x})$ or unreduced $(n=3 \mathrm{x})$. In theory, the union of these gametes with the unreduced $(n=2 \mathrm{x})$ gametes from diploids $(2 \mathrm{x})$ or tetraploids $(4 \mathrm{x})$ will yield pentaploid 
and hexaploid individuals, respectively. Moreover, individuals with higher than expected ploidies have also been reported in other species (Ramsey \& Schemske, 1998). In crosses of Andropogon gerardii (Poaceae), $31.5 \%$ of the individuals produced in $9 \mathrm{x} \times 9 \mathrm{x}$ crosses had ploidies greater than 9x (Norrmann et al., 1997). In addition, $5 \mathrm{x}$ progeny were reported in $3 \mathrm{x} \times 4 \mathrm{x}$ crosses in Petunia (Dermen, 1931). What is surprising about the present result is that individuals of $C$. angustifolium with five chromosome sets have never been reported in natural populations and hexaploid $C$. angustifolium have been reported only from Japan (Mosquin, 1967). Clearly, high-level ploidies can be produced, but the reasons for their absence in North America remains unknown.

The results presented in this study have important implications for the evolution of tetraploidy in plants. The crossing experiment indicates that triploids produce functional gametes and can participate in mating with diploids and tetraploids. This work reinforces previous research on the frequency of cytotypes in natural populations (Husband \& Schemske, 1998) and their fitnesses (Burton \& Husband, 2000), which suggests that triploids are an important component of mixed populations and that triploid block is not complete in this species. While triploids have been observed in other polyploid species (Zohary \& Nur, 1959; Burton \& Husband, 1999), in most field studies and all but one theoretical model (Felber \& Bever, 1997), they are considered relatively unimportant to tetraploid evolution. However, the present work shows that triploids provide a large source of $x, 2 x$, and $3 x$ gametes to the gamete pool and are perhaps the most important pathway of recurrent tetraploid formation. Assuming random mating and equal cytotype frequencies, $0.04 \%$ of the tetraploids produced in any given generation will be produced directly through $2 \mathrm{x} \times 2 \mathrm{x}$ matings, whereas $77 \%$ will be produced in matings that involve triploids.

Using simulations, we examined whether the presence of functional triploids would be sufficient to alter the evolutionary dynamics of mixed cytotype populations and enhance the spread of tetraploids. This approach differed from that of Felber \& Bever (1997) in that they assumed that triploids produced equal frequencies of $\mathrm{x}$ and $2 \mathrm{x}$ pollen, and no $3 \mathrm{x}$ pollen. In contrast, the present data suggest that $3 x$ pollen may not be uncommon. Simulation results herein, however, were similar in that the presence of functional triploids resulted in a stable equilibrium of diploid, tetraploid and triploid individuals. Moreover, as the fitness of triploids increased, the conditions for the spread of tetraploids generally improved, although the specific pattern depended on the relative fitnesses of diploids and tetraploids. When tetraploid fitness was less than diploid fitness, diploids persisted in the population and triploids were more common that tetraploids. When the relative fitness of tetraploids was one, increasing triploid fitness led to the exclusion of diploids and tetraploids were the most common cytotype. These results suggest that the production of tetraploids via triploid matings is sufficiently high to alter the fate of tetraploids in a diploid population.

However, in simulations using the fitness relationships measured in greenhouse populations of $C$. angustifolium, the presence of triploids had little impact on the likelihood of tetraploid establishment compared to theoretical models lacking triploids (Felber, 1991). In the absence of unreduced gametes, tetraploids are expected to spread to fixation once they have exceeded a frequency of $50 \%$. In our study, the equilibrium frequency of tetraploids was non-negligible when their initial frequency was $>40 \%$ and at higher frequencies some diploids still persisted. This suggests that, while recurrent tetraploid production via triploids alters the evolutionary dynamics of mixed populations, under most conditions it is insufficient to overcome the large fitness disadvantage experienced by triploids and tetraploids in $C$. angustifolium.

The significance of intercytotype matings for $C$. angustifolium is determined not only by their fecundity and resulting offspring ploidies, but also by the likelihood of such matings occurring in natural populations. In allopatric populations, which predominate in the northern and southern portions of the geographical range, most matings are assortative and intercytotype crosses are therefore of little consequence. Within the contact zone, however, diploids, triploids and tetraploids are found with regular occurrence (Husband \& Schemske, 1998; Husband, unpubl.), often in close proximity. Matings between cytotypes in sympatry are often restricted by divergent flowering times and pollinator behaviour (Husband \& Schemske, 2000). However, the existence of triploids is evidence that intercytotype mating occurs and the overlap in flowering times, particularly between triploids and tetraploids (Burton \& Husband, 2000), suggesting that matings between diploids, triploids and tetraploids may have important consequences for the nature of interactions between ploidies, the likelihood of cytotype coexistence and the geographical position of the contact zone.

\section{Acknowledgements}

We thank A. Bauman and C. Hussell for laboratory assistance and the Natural Science and Engineering Research Council of Canada for financial support. 


\section{References}

ARUMUGANATHAN, K. AND EARL, E. D. 1991. Estimation of nuclear DNA content of plants by flow cytometry. Plant Mol. Biol., 9, 229-233.

BRETAGNOLLE, F. AND THOMPSON, J. D. 1995. Tansley Review no. 78. Gametes with the somatic chromosome number: mechanisms of their formation and role in the evolution of autopolyploid plants. New Phytol., 129, 1-22.

BURTON, T. L. AND HUSBAND, B. C. 1999. Cytotype distribution in the autopolyploid Galax urceolata (Diapensiaceae). Heredity, 82, 381-390.

BURTON, T. L. AND HUSBAND, B. C. 2000. Fitness differences among diploids and tetraploids and their triploid progeny in Chamerion angustifolium (Onagraceae): mechanisms of inviability and implications for polyploid evolution. Evolution, 54, 1182-1191.

Dermen, H. 1931. Polyploidy in Petunia. Am. J. Bot., 18, $250-261$

FELBER, F. 1991. Establishment of a tetraploid cytotype in a diploid population: effect of relative fitness of the cytotypes. J. Evol. Biol., 4, 195-207.

FELBER, F. AND BEVER, J. D. 1997. Effect of triploid fitness on the coexistence of diploids and tetraploids. Biol. J. Linn. Soc., 60, 95-106.

FLINT, E. 1980. Ecology and distribution of diploid and tetraploid Epilobium angustifolium (fireweed) in the Beartooth Mountains of Wyoming and Montana. Ph.D. Thesis, Duke University, Durham, NC.

FOWLER, N. L. AND LEVIN, D. A. 1984. Ecological constraints on the establishment of a novel polyploid in competition with its diploid progenitor. Am. Nat., 124, 703-711.

HARLAN, J. R. AND DE WET, J. M. 1975. On O. Winge and a prayer: the origins of polyploidy. Bot. Rev., 41, 361-390.

HUSBAND, B. C. 2000. Constraints on polyploid evolution: a test of the minority cytotype exclusion principle. Proc. R. Soc. B, 267, 217-223.

HUSBAND, B. C. AND SCHEMSKE, D. W. 1997. The effect of inbreeding in diploid and tetraploid populations of Epilobium angustifolium (Onagraceae): implications for the genetic basis of inbreeding depression. Evolution, 51, 737-746.

HUSBAND, B. C. AND SCHEMSKE, D. W. 1998. Cytotype distribution at a diploid-tetraploid contact zone in Chamerion angustifolium (Onagraceae). Am. J. Bot., 85, 1688-1694.
HUSBAND, B. C. AND SCHEMSKE, D. W. 2000. Ecological mechanisms of reproductive isolation and coexistence of diploid and tetraploid Chamerion angustifolium. J. Ecol., 88, $1-14$.

KEELER, K. H., KWANKIN, B., BARNES, P. W. AND GALBRAITH, D. W. 1987. Polyploidy polymorphism in Andropogon gerardii. Genome, 29, 374-379.

LEVIN, D. A. 1975. Minority cytotype exclusion in local plant populations. Taxon, 24, 35-43.

MACEIRA, N. O., DE HAAN, A. A., LUMARET, R., BILLON, M. AND DELAY, J. 1992. Production of $2 n$ gametes in diploid subspecies of Dactylis glomerata L. 1. Occurrence and frequency of 2n pollen. Ann. Bot., 69, 335-343.

MosQuin, T. 1966. A new taxonomy for Epilobium angustifolium L. (Onagraceae). Brittonia, 18, 167-188.

MOSQUIN, T. 1967. Evidence for autopolyploidy in Epilobium angustifolium (Onagraceae). Evolution, 21, 713-719.

MOSQUIN, T. AND SMALl, E. 1971. An example of parallel evolution in Epilobium (Onagraceae). Evolution, 25, 678-682.

NORRMANN, G. A., QUARIN, C. L. AND KEELER, K. H. 1997. Evolutionary implications of meiotic chromosome behavior, reproductive biology, and hybridization in $6 x$ and $9 x$ cytotypes of Andropogon gerardii (Poaceae). Am. J. Bot., 84, 201-207.

RAMSEY, J. AND SCHEMSKe, D. W. 1998. Pathways, mechanisms and rates of polyploid formation in flowering plants. Ann. Rev. Ecol. Syst., 29, 467-501.

RODRIGUEZ, D. J. 1996. A model for the establishment of polyploidy in plants: viable but infertile hybrids, iteroparity, and demographic stochasticity. J. Theor. Biol., 180, 189-196.

SATO, T. N., MACEIRA, N. O., LUMARET, R. AND JACQUARD, P. 1993. Flowering characteristics and fertility of interploidy progeny from normal and $2 \mathrm{n}$ gametes in Dactylis glomerata. New Phytol., 124, 309-319.

SOltis, D. E. AND SOLTIS, P. S. 1999. Polyploidy: recurrent formation and genome evolution. Trends Ecol. Evol., 14, 348-352.

ZOHARY, D. AND NUR, U. 1959. Natural triploids in the orchard grass, Dactylis glomerata L., polyploid complex and their significance for gene flow from diploid to triploid levels. Evolution, 13, 311-317. 